\title{
Bridging Faultlines by Valuing Diversity: Diversity Beliefs, Information Elaboration, and Performance in Diverse Work Groups
}

\author{
Astrid C. Homan, Daan van Knippenberg, Gerben A. Van Kleef and \\ Carsten K. W. De Dreu
}

\begin{tabular}{|l|l|}
\hline \multicolumn{2}{|l|}{ ERIM REPORT SERIES RESEARCH IN MANAGEMENT } \\
\hline ERIM Report Series reference number & ERS-2006-071-ORG \\
\hline Publication & September 2006 \\
\hline Number of pages & 42 \\
\hline Persistent paper URL & http://hdl.handle.net/1765/8496 \\
\hline Email address corresponding author & ahoman@fsw.leidenuniv.nl \\
\hline Address & Erasmus Research Institute of Management (ERIM) \\
& RSM Erasmus University / Erasmus School of Economics \\
& Erasmus Universiteit Rotterdam \\
& P.O.Box 1738 \\
& 3000 DR Rotterdam, The Netherlands \\
& Phone: $\quad+31104081182$ \\
& Fax: $\quad+31104089640$ \\
& Email: info@erim.eur.nl \\
& Internet: $\quad$ www.erim.eur.nl \\
\hline
\end{tabular}

Bibliographic data and classifications of all the ERIM reports are also available on the ERIM website: www.erim.eur.nl 


\section{ERASMUS RESEARCH INSTITUTE OF MANAGEMENT}

\section{REPORT SERIES}

\section{RESEARCH IN MANAGEMENT}

\begin{tabular}{|l|l|}
\hline \multicolumn{2}{|l|}{ ABSTRACT AND KEYWORDS } \\
\hline Abstract & $\begin{array}{l}\text { Although there are numerous potential benefits to diversity in work groups, converging } \\
\text { dimensions of diversity often prevent groups from exploiting this potential. In a study of } \\
\text { heterogeneous decision-making groups, we examined whether the disruptive effects of diversity } \\
\text { faultlines can be overcome by convincing groups of the value in diversity. Groups were either } \\
\text { persuaded of the value of diversity or of the value of similarity for group performance, and they } \\
\text { were provided with either homogeneous or heterogeneous information. As expected, } \\
\text { informationally diverse groups performed better when they held pro-diversity rather than pro- } \\
\text { similarity beliefs, whereas the performance of informationally homogeneous groups was } \\
\text { unaffected by diversity beliefs. This effect was mediated by group-level information elaboration. }\end{array}$ \\
\hline Implications for diversity management in organizations are discussed.
\end{tabular}


Running head: DIVERSITY BELIEFS AND PERFORMANCE

Bridging Faultlines by Valuing Diversity:

Diversity Beliefs, Information Elaboration, and Performance in Diverse Work Groups

Astrid C. Homan

University of Amsterdam

Daan van Knippenberg

Erasmus University Rotterdam

Gerben A. Van Kleef and Carsten K. W. De Dreu

University of Amsterdam

Astrid C. Homan, Department of Psychology, University of Amsterdam; Daan van Knippenberg, RSM Erasmus University, Erasmus University Rotterdam; Gerben A. Van Kleef and Carsten K. W. De Dreu, Department of Psychology, University of Amsterdam.

Astrid C. Homan is now at Leiden University, Department of Social Sciences, Section Work and Organizational Psychology.

Correspondence concerning this article should be addressed to Astrid C. Homan, Leiden University, Section Social and Organizational Psychology, PO box 9555, 2300 RB Leiden, The Netherlands, pho +31 71 5273718, fax +31 20 2573758, email ahoman@fsw.leidenuniv.nl. 


\begin{abstract}
Although there are numerous potential benefits to diversity in work groups, converging dimensions of diversity often prevent groups from exploiting this potential. In a study of heterogeneous decision-making groups, we examined whether the disruptive effects of diversity faultlines can be overcome by convincing groups of the value in diversity. Groups were either persuaded of the value of diversity or of the value of similarity for group performance, and they were provided with either homogeneous or heterogeneous information. As expected, informationally diverse groups performed better when they held pro-diversity rather than pro-similarity beliefs, whereas the performance of informationally homogeneous groups was unaffected by diversity beliefs. This effect was mediated by grouplevel information elaboration. Implications for diversity management in organizations are discussed.
\end{abstract}

KEY WORDS: DIVERSITY, FAULTLINES, DIVERSITY BELIEFS, INFORMATION ELABORATION, TEAM PERFORMANCE 
Bridging Faultlines by Valuing Diversity:

Diversity Beliefs, Information Elaboration, and Performance in Diverse Work Groups When important decisions have to be made, organizations often turn to groups. Especially when group members differ with respect to the information and expertise they bring to the table, groups may outperform individuals in terms of the quality of the decisions they reach (Argote, Gruenfeld, \& Naquin, 2000; Ilgen, 1999; see also Hinsz, Tindale, \& Vollrath, 1997). Organizations therefore increasingly rely on cross-functional work groups and project teams in an attempt to stimulate innovation, solve problems, and make decisions. Often, informational diversity within such teams comes hand in hand with differences on other dimensions, such as demographic characteristics and deeply held values and beliefs (Harrison, Price, \& Bell, 1998; Jehn, Northcraft, \& Neale, 1999; Milliken \& Martins, 1996; Phillips, 2003; Williams \& O'Reilly, 1998). When different dimensions of diversity converge (e.g., when all team members with technical expertise are male and those with knowledge about marketing and sales are female) so-called diversity faultlines emerge that may disrupt group processes (Lau \& Murnighan, 1998).

A number of studies have documented negative effects of diversity faultlines on group functioning (e.g., Homan, van Knippenberg, Van Kleef, \& De Dreu, 2006; Lau \& Murnighan, 2005; Phillips, Mannix, Neale, \& Gruenfeld, 2004; Thatcher, Jehn, \& Zanutto, 2003. Accordingly, diversity faultlines are generally believed to have a negative impact on group processes and performance (for a review, see van Knippenberg \& Schippers, in press). In the present paper, we challenge the widely shared assumption that groups with diversity faultlines cannot benefit from their informational diversity (cf. Jehn et al., 1999) by focusing on the role of group members' beliefs about diversity. We argue and show experimentally that groups with diversity faultlines may effectively use their informational diversity when group members believe in the value of diversity. 


\section{Informational Diversity and Diversity Faultlines}

Informational diversity is defined as "differences in knowledge bases and perspectives that members bring to the group" (Jehn et al., 1999, p. 743), and has also been referred to as functional or knowledge diversity (Pelled, Eisenhardt, \& Xin, 1999; Phillips et al., 2004). Van Knippenberg, De Dreu, and Homan (2004) argue that informational diversity can enhance group performance by stimulating the elaboration of task-relevant information and perspectives. Building on the conceptualization of groups as information processors (Hinsz et al., 1997), they define elaboration as the exchange of information and perspectives, individual-level processing of the information and perspectives, feeding back the results of this individual-level processing into the group, and discussion and integration of their implications. This deeper and more extensive consideration of task-relevant information may lead diverse groups to outperform more homogeneous groups on tasks with clear information processing and decision-making requirements (e.g., Bowers, Pharmer, \& Salas, 2000; Jehn et al., 1999).

As an example of this process of elaboration in diverse groups, consider crossfunctional surgical teams consisting of surgeons, radiologists, anaesthetists, and surgical nurses. High quality performance requires that team members use their own expertise to inform the other team members about the different issues involved in the specific operation (e.g., how long the operation will take, what kind of surgical instruments are needed, where the fracture is), carefully process the information, opinions, and perspectives introduced by other team members to understand the implications for their own area of medical expertise, feed these implications back to the team, and integrate these implications to provide the best possible care for the patient.

Although diverse perspectives within a team can lead to enhanced team functioning through information elaboration, this effect may be reduced or even reversed when 
informational diversity converges with other diversity dimensions such as gender, personality differences, or attitudes and values. When different dimensions of diversity converge, the covariation of differences creates a diversity faultline that may elicit subgroup categorization-an "us-them" distinction (Lau \& Murnighan, 1998; van Knippenberg, De Dreu et al., 2004; cf. Turner, Hogg, Oakes, Reicher, \& Wetherell, 1987). Such subgroup categorizations can disrupt group processes by rendering group members less trusting of and motivated to cooperate with other group members, less committed to the group, increasing interpersonal tensions and conflict, and lowering communication (e.g., Earley \& Mosakowski, 2000; Lau \& Murnighan, 2005; Li \& Hambrick, 2005; for a review, see van Knippenberg \& Schippers, in press). Thus, although diversity may stimulate group performance through information elaboration, it may also undermine group performance through social categorization processes (Williams \& O'Reilly, 1998), and the latter is more likely to occur when dimensions of diversity converge to create diversity faultlines. However, and in contrast with this commonly accepted view, we propose that the performance of groups with diversity faultlines need not necessarily be impeded. Rather, we argue that the performance of such groups depends on group members' beliefs about the value of diversity.

\section{Diversity Beliefs}

Several authors have noted that people may differ in their beliefs about and attitudes toward diversity (Hostager \& De Meuse, 2002; Strauss, Connerley, \& Ammermann, 2003; van Knippenberg \& Haslam, 2003), and that organizational climates and cultures may differ in the extent to which they value diversity (Cox, 2003; Ely \& Thomas, 2001; Jackson et al., 1992; Kossek \& Zonia, 1993; Mor Barak, Cherin, \& Berkman, 1998). These studies have advanced the theoretical notion that beliefs, attitudes, climates, or cultures valuing diversity are needed to harvest the benefits of diversity, and have focused on the measurement and the determinants of diversity beliefs, attitudes, and climates. However, so far a quantitative test 
of the influence of diversity beliefs and related constructs on group processes and performance in diverse teams has not been conducted. The present study provides such a test.

Diversity beliefs can be defined as beliefs about the value of diversity to work group functioning (van Knippenberg \& Haslam, 2003). Contingent on such beliefs, diversity may affect the extent to which one's own work group is perceived as being a good group--where good may refer to (expectations of) task performance as well as to other aspects of group functioning. Diversity beliefs may thus inform responses to work group diversity, and lead people to respond more favorably to work group diversity the more they believe in the value of diversity for work group functioning (van Knippenberg, Haslam, \& Platow, 2004). In support of this proposition, van Knippenberg, Haslam et al. showed in a survey and a laboratory experiment that the relationship between diversity and group members' identification with their work group was moderated by diversity beliefs. When individuals believed that diversity was beneficial for the task at hand, diversity was positively related to group identification, whereas diversity tended to be negatively related to identification when individuals believed in the value of similarity. In similar vein, in a qualitative study Ely and Thomas (2001) observed that when an organization's perspective on diversity emphasized cultural diversity as a valuable resource for the organization, members reported feeling more valued and respected, reported a higher quality of intergroup relations, and felt that they were more successful than when the organization's perspective was not focused on the potential value of diversity.

Pro-diversity beliefs may thus remove an important barrier for diverse groups to benefit from their informational diversity. Van Knippenberg, De Dreu et al. (2004) propose that intergroup biases engendered by subgroup categorization disrupt the elaboration of taskrelevant information in diverse groups and thus stand in the way of groups' effective use of their informational resources. They further argue, however, that salient subgroup 
categorizations (i.e., in a team with diversity faultlines) need not necessarily elicit intergroup bias. Pro-diversity beliefs (as compared to pro-similarity beliefs) may lead group members to respond favorably to the group and its diverse membership. Pro-diversity beliefs may thus increase the likelihood that groups benefit from their diversity by inviting group members to actively solicit new information and perspectives from fellow group members, and thereby stimulate performance.

\section{The Present Study}

Previous work thus suggests that when diversity is seen as valuable to group functioning, group members may respond more positively to diversity. In the present study we extend this line of work by providing a quantitative test of the effects of diversity beliefs on groups' use of their informational diversity. Because the potential positive effects of informational differences are more likely to be impeded when dimensions of diversity combine to form a faultline (Lau \& Murnighan, 1998), we focused on groups with a diversity faultline. It has been found that in teams with a strong faultline the negative effects of diversity in general outweigh the positive effects (e.g., Gibson \& Vermeulen, 2005; Lau \& Murnighan, 1998; Thatcher et al., 2003). We thus test the impact of diversity beliefs in a context where disruptive effects might be expected in the absence of pro-diversity beliefs.

The positive effects of work group diversity on group performance are likely to emerge primarily in groups performing relatively complex tasks that require information processing, creativity, and collaborative decision-making, where the exchange of diverse task-related information and perspectives may stimulate groups' thorough consideration of the task at hand (Bowers et al., 2000; Jehn et al., 1999; van Knippenberg, De Dreu et al., 2004). We therefore tested the interactive effects of diversity beliefs and informational diversity in a group decision-making context. We hypothesized that even under faultline conditions groups may make good use of informational diversity when they hold beliefs favoring group 
diversity rather than homogeneity. Because especially informationally diverse groups need to elaborate task-relevant information and perspectives to perform well (i.e., they need to exchange and integrate diverse information and perspectives that are already shared in informationally homogeneous groups), we expected performance to be affected more by diversity beliefs in informationally diverse groups than in informationally homogeneous groups. Based on this reasoning we advance the following three hypotheses.

Hypothesis 1: Diversity beliefs moderate the effect of informational diversity on group performance. Informationally diverse groups perform better when group members believe in the value of diversity rather than similarity, whereas the performance of informationally homogeneous groups is less affected by diversity beliefs.

Hypothesis 2: Diversity beliefs moderate the effect of informational diversity on elaboration of task-relevant information. Informationally diverse groups engage in more elaboration of task-relevant information when group members believe in the value of diversity rather than similarity, whereas elaboration in informationally homogeneous groups is less affected by diversity beliefs.

Hypothesis 3: The effect of diversity beliefs on performance in informationally diverse groups is mediated by elaboration of task-relevant information.

These hypotheses were tested in an experimental study of four-person groups that worked interactively on a complex decision-making task in which they had to generate decision alternatives and decide about the alternatives adopted. We decided to adopt an experimental approach for two reasons. First, testing our hypotheses in an experimental setting allowed us to draw conclusions about causality. Second, this approach allowed us to directly assess relevant group processes through behavioral coding of audio-video recordings of group interaction, rather than having to rely on the retrospective self-report data that are more customary in field research. This method thus yields a more direct and objective 
assessment of the group processes leading to group performance (Weingart, 1997).

$$
\text { Method }
$$

\section{Sample and Design}

A total of 184 students (92 females and 92 males) of the University of Amsterdam participated in the experiment for course credit or monetary compensation (10 euro, approximately 12 USD). The mean age of the participants was 21 years. The participants were randomly assigned to gender-diverse four-person groups (always consisting of two males and two females), and these groups were then randomly assigned to one of the conditions of a 2 (informational diversity: heterogeneity vs. homogeneity) x 2 (diversity beliefs: pro-similarity vs. pro-diversity) factorial design. A total of 46 groups participated in the experiment. One group could not be videotaped due to technical problems. The Task

The task that was used required groups to generate and select ideas. The task was inspired by a decision-making task developed by Johnson and Johnson (1982). Groups were instructed to come up with as many useful items as possible needed to survive in a desert, based on information provided to them before the task. The only rules were that (1) the items should be portable and (2) participants had to explain why the selected items were important for surviving in a desert. The groups thus had to work on a list of high quality options by generating options, discussing them, and determining which options were good enough to put on the list. A pretest showed that this task was not gender-related. ${ }^{1}$

\section{Procedure}

Creating a faultline. Upon arrival, participants were seated in a room in same-gender pairs. At this time, they could not see the other two group members. Participants individually read instructions stating that the study aimed to determine the effect of personality on cooperation. Then, the participants were asked to fill out a personality test. After filling out 
the questionnaire, their answers were supposedly analyzed, and their personality type determined. After about ten minutes, the experimenter returned with the results. The bogus feedback that male participants received stated that they had an "M" personality type. Female participants received bogus feedback stating that they had an "F" personality type. They then received some superficial information about their personality type. The description of the personality type consisted of eight gender-specific traits (e.g., strong, adventurous for males; emotional, considerate for females; Willemsen \& Fischer, 1996). Next, the participants read that there was a chance that they would be working in a group with people with a different personality type, and they were given three traits of people with a different personality type (e.g., females read that people with an M personality type were adventurous).

Finally, seating was used to make the faultline more salient. After participants had read the information about the task, they were seated in a new room in which the group would perform the task. Same-gender group members were always seated next to each other at a rectangular table, facing the opposite-gender members. Such converging of diversity dimensions (i.e., gender, [bogus] personality feedback, seating) results in high withinsubgroup similarity and high between-subgroup differences, which makes subgroup categorization more likely (Gaertner, Mann, Murrell, \& Dovidio, 1989; Turner et al., 1987; van Knippenberg, De Dreu et al., 2004). We thus created a perfect faultline, in the sense that differences in gender, (bogus) personality feedback, and seating arrangement were perfectly correlated (cf. Lau \& Murnighan, 1998; Thatcher et al., 2003). Previous research has shown that this specific convergence of diversity attributes elicits a strong faultline and evokes disadvantageous group processes (Homan et al., 2006).

Manipulation of informational diversity. Then, participants received the instructions for the decision-making task and some information about surviving in the desert. This information was used to manipulate informational diversity. Based on expert information 
(Johnson \& Johnson, 1982), twelve different categories of information concerning surviving in a desert were distinguished (e.g., make sure you do not dry out, create shade, batteries overheat in the heat). In the information package, these twelve different categories were mentioned in such a way that thoughtful use of the information could help in determining which items would be useful for surviving in a desert. We used standard procedures to manipulate the homogeneous versus heterogeneous information within the groups (see e.g., Gruenfeld, Mannix, Williams, \& Neale, 1996; Stasser \& Titus, 1985). In the informationally homogeneous condition, all group members individually received the twelve different categories of information (i.e., all the available information was shared among all the group members). In the informationally diverse conditions, eight of these categories of information were divided into two equally informative parts (part A and part B). ${ }^{2}$ Two group members received part A and two group members received part B. Same-gender group members always received the same information (further enhancing the faultline). The four remaining information items were shared among the group members. The individual group members in the informationally diverse conditions thus received eight information items. Four of these items were shared among all four group members, four information items were given only to the female group members, and four information items were given only to the male group members. Again, at the group level, the group received twelve items of information (i.e., four shared items + four items for the males + four items for the females). In other words, groups in all conditions received the same set of information--only the distribution of information across group members differed between conditions.

Manipulation of diversity beliefs. After the personality test and before the decisionmaking task, participants received some additional information about working in teams. Through this information, diversity beliefs were manipulated. Groups in the pro-diversity beliefs condition read that research had shown that gender-diverse groups typically perform 
better on decision-making tasks, and experience more pleasant group processes than genderhomogeneous groups. Conversely, groups in the pro-similarity beliefs condition read that research had shown that gender-homogeneous groups typically perform better on decisionmaking tasks, and experience more pleasant group processes than gender-diverse groups. Following this information, the participants received a short introduction to the task and some feedback about their personality type. Finally, participants were given a questionnaire to check the manipulation of diversity beliefs. After reading all the information, the participants were brought to another room and were seated together. They were then given 30 minutes to work on the decision-making task. Groups were videotaped during interaction. Upon completion of the task, a questionnaire was administered to check the manipulation of informational diversity. Then, participants were debriefed and thanked.

\section{Dependent Variables}

Manipulation checks. We checked the manipulation of informational diversity with four items (e.g., "during the group task, the group members regularly said things I did not know"). Principal components analysis (PCA) revealed that these four items all loaded on one factor (factor loadings between .80 and .84). Reliability analysis showed that the four questions formed a reliable scale $(\alpha=.86 ; M=3.48, S D=1.19)$. We checked the manipulation of diversity beliefs with four items (e.g., "groups that are diverse on gender usually perform better than groups that are homogeneous on gender"). PCA revealed that these four items all loaded on one factor (factor loadings between .82 and .84). The four items formed a reliable scale $(\alpha=.86 ; M=4.22, S D=1.42)$. All responses were given on Likert scales ranging from $1=$ totally disagree to $7=$ totally agree .

Performance. Performance was determined by calculating the mean score per item for each group. In the original task, twelve categories of items were distinguished. Based on these categories a coding scheme was developed by which performance could be calculated. 
Better items (i.e., items that were ranked higher in the expert ranking reported by Johnson \& Johnson, 1982) received a higher score, with the highest possible score being 12 points. For example, when the group decided they would bring a magnetic compass, they received a score of 1 , because the information clearly indicated that groups should not walk. Two independent raters coded the items generated by the groups, providing overlapping ratings of $21 \%$ of the groups to determine inter-rater agreement. We assessed inter-rater reliability by computing intraclass correlations (ICC, Shrout \& Fleiss, 1979). The average intra-class correlation for the two raters was .91, which is considered "excellent" according to the criteria developed by Cicchetti and Sparrow (1981). Finally, because instructions emphasized quality rather than quantity, we divided the score by the number of items generated to ensure that groups that came up with a lot of low-quality items would not get higher scores than groups that came up with fewer high-quality items. Thus, performance scores reflect quality of performance, not quantity. ${ }^{3}$

Information elaboration. Information elaboration at the group level involves the degree to which information is shared and processed by the group members (van Knippenberg, De Dreu et al., 2004; Hinsz et al., 1997). Elaboration of information was measured by coding the videotapes of 45 groups (one group had to be omitted from the analyses due to technical problems). The coding scheme was developed based on the different information categories as described under the manipulation of informational diversity. We expected that the differences between groups receiving homogeneous and groups receiving heterogeneous information would only be visible when examining the unshared information items. Thus, because we did not expect (or find) differences between groups on the elaboration of shared information items, we focused on the eight information categories that were unshared in the heterogeneous information conditions. ${ }^{4}$

The coding scheme was constructed as follows. The higher the score, the more an 
information item was elaborated upon. A score of "0" was given when an information item was not mentioned at all during the discussion. A score of "1" was given when information was mentioned, but none of the other members reacted to it (i.e., if the information was only exchanged). A score of "2" was given when one of the members mentioned an item of information and at least one of the other members reacted to it (e.g., by saying something like "OK" or by nodding), but after this the group still failed to ask questions about it or integrate it with the other information. A score of "3" was given when a unshared piece of information was mentioned by one of the group members and one or more other members clearly responded by asking a question about it (e.g., "Why is it important to give light signals?"). A score of "4" was given when the mentioning of an unshared information item resulted in a conclusion about whether something was important or not (e.g., "ah, a mirror must be important, you can use the light of the sun to signal with that."). Finally, a score of "5" was given when the information item was combined with another piece of unshared information by one of the other group members (e.g., "Wait a minute, we need protection from the sun as well, right? Why don't we take an aluminum tent with us? That will create shade and will reflect light as well."). We determined the highest level of information elaboration for each information item (from 0 to 5); the total elaboration was then determined by computing the sum of information elaboration for the eight information categories. The maximum number of points that could be obtained thus was 8 items x 5 points is 40 points. Two independent raters, blind to the experimental conditions and hypotheses, coded the videotapes. They provided double ratings of twenty percent of the videotapes to check interrater reliability. The average intra-class correlation for the two raters was .96, which is considered excellent (Cicchetti \& Sparrow, 1981). 


\section{Treatment of the Data}

We used analysis of variance to test Hypotheses 1 and 2 and regression analysis to test Hypotheses 3. Manipulation checks were measured at the individual level, but because the individuals were working in four-person groups their answers are probably not independent (Kashy \& Kenny, 2000). Therefore, we aggregated individuals' answers to the group level. To control whether this aggregation was appropriate, we computed ICC(1), ICC(2), and $r_{\mathrm{wg}}$ (e.g., Bliese, 2000). First, to test whether the groups could be reliably differentiated on the manipulation checks, we estimated ICC(2) values. Following Glick's (1985) recommendations, ICC(2) values were acceptable (.79 for the informational diversity check; .68 for the diversity beliefs check). To further support aggregation to the group level, ICC(1) and $r_{\mathrm{wg}}$ values were calculated. Both for the manipulation check of informational diversity (ICC[1] value $.49, F[45,138]=4.81, p<.01$, and $r_{\text {wg }}$ value .71 ), and manipulation check of diversity beliefs (ICC[1] value $.35, F[45,138]=3.14, p<.01$, and $r_{\mathrm{wg}}$ value .70 ) the obtained values justify aggregation to the group level (George, 1990).

\section{Manipulation Checks}

Informational diversity. Groups in the homogeneous information condition $(M=2.63$, $S D=.67)$ indicated that the information that the group members received was less diverse than did groups in the heterogeneous information condition $(M=4.33, S D=.98), F(1,42)=$ $64.40, p<.01, \eta^{2}=.59$. The manipulation check for informational diversity was not influenced by diversity beliefs, $F(1,42)=0.55$, $n s . \eta^{2}=.01$, nor by the interaction between informational diversity and diversity beliefs, $F(1,42)=2.26, n s, \eta^{2}=.05$.

Diversity beliefs. Groups with pro-diversity beliefs $(M=4.85, S D=.84)$ indicated that diverse teams would perform and cooperate better than groups with pro-similarity beliefs ( $M$ $=3.64, S D=.74), F(1,42)=25.87, p<.01, \eta^{2}=.38$. The manipulation check for diversity beliefs was not influenced by informational diversity, $F(1,42)=0.02, n s, \eta^{2}=.00$, or the 
interaction between informational diversity and diversity beliefs, $F(1,42)=0.40, n s, \eta^{2}=.01$.

\section{Performance}

There was no main effect of informational diversity on performance--groups with diverse information $(M=6.67, S D=.98)$ showed similar levels of performance as groups with homogeneous information $(M=6.62, S D=.97), F(1,42)=0.28, n s, \eta^{2}=.00$. We did find a significant main effect of diversity beliefs, indicating that groups with pro-diversity beliefs performed better $(M=6.95, S D=.96)$ than did groups with pro-similarity beliefs $(M=$ 6.36, $S D=.89), F(1,42)=5.27, p<.05, \eta^{2}=.11$. Moreover, in support of Hypothesis 1 , the interaction between diversity beliefs and informational diversity was significant, $F(1,42)=$ 4.25, $p<.05, \eta^{2}=.09$. Means and standard deviations pertaining to this interaction are shown in Table 1. Simple effects analysis showed that groups with diverse information and prodiversity beliefs outperformed groups with diverse information and pro-similarity beliefs, $F(1,42)=4.27, p<.05, \eta^{2}=.18$. Groups with homogeneous information were not influenced by diversity beliefs, $F(1,42)=.03, n s, \eta^{2}=.00$. This interaction is depicted in Figure 1.

\section{Information Elaboration}

We obtained a significant main effect of informational diversity on information elaboration, showing that groups with diverse information $(M=28.29, S D=6.39)$ elaborated more information than did groups with homogeneous information $(M=24.13, S D=3.91)$, $F(1,41)=7.13, p<.05, \eta^{2}=.14$. We also found a significant main effect of diversity beliefs, revealing that groups with pro-diversity beliefs $(M=27.59, S D=6.21)$ elaborated more information than did groups with pro-similarity beliefs $(M=24.61, S D=4.54), F(1,41)=$ 4.39, $p<.05, \eta^{2}=.08$. More importantly, these main effects were qualified by a significant diversity beliefs by informational diversity interaction, $F(1,41)=6.61, p<.05, \eta^{2}=.33$ (see Table 1 for means and standard deviations). As predicted in Hypothesis 2, groups with diverse information and pro-diversity beliefs elaborated more information than did groups 
with diverse information and pro-similarity beliefs, $F(1,41)=10.96, p<.01, \eta^{2}=.21$. Groups with homogeneous information were not influenced by diversity beliefs, $F(1,41)=$ $.22, n s, \eta^{2}=.01$. This interaction is shown in Figure 2 .

\section{Mediation Analysis}

Hypothesis 3 predicted that diversity beliefs moderate the effect of informational diversity on performance through their impact on information elaboration in informationally diverse groups. To test this proposed pattern of mediation, we followed procedures suggested by Baron and Kenny (1986) and extended by Hull, Tedlie, and Lehn (1992). According to Baron and Kenny (1986), four requirements should be met to establish mediation. First, there should be a significant effect of the independent variable(s) on the dependent variable. Second, there should be an effect of the independent variable(s) on the mediator. Third, the mediator should predict the dependent variable. Finally, the effect of the independent variable(s) should be reduced to non-significance when controlling for the mediator.

More recently, Hull et al. (1992; also see Muller, Judd, \& Yzerbyt, 2005; Yzerbyt, Muller, \& Judd, 2004) have proposed an important extension of these procedures. They suggest that in mediation analysis it may also be relevant to control for the possibility that the proposed mediator is not linearly related to the dependent variable but instead more strongly related to the dependent variable under certain conditions than under others. When this is the case, entering the mediator as a linear covariate violates the statistical assumption of homogeneity of regression slopes (i.e., the assumption that the slopes of the regression lines are the same in each group). Inclusion of the "covariate interaction" (i.e., the interaction between an independent variable and the proposed mediator; Hull et al., 1992) then yields a more appropriate test of mediation (i.e., a test that does not assume homogeneity of regression slopes across conditions; cf. Stevens, 1996) than an analysis that only includes the "main effect" of the proposed mediator (Hull et al., 1992; Muller et al., 2005; Yzerbyt et al., 
2004). Our theoretical analysis points to the possibility that information elaboration is more positively related to performance under conditions of informational diversity (i.e., where groups need to exchange and integrate information to reach optimal decisions) than under conditions of informational homogeneity (i.e., where groups in principal can rely more on the pooling of pre-discussion preferences and performance therefore may be less contingent on information elaboration). We therefore controlled for this possibility by including the "covariate interaction" between informational diversity and elaboration in our mediational analysis.

In sum, to test our mediation model we followed the four steps described by Baron and Kenny (1986) but also included the covariate interaction between information elaboration and informational diversity in the analysis, as suggested by Hull et al. (1992). We have already established that informational diversity and diversity beliefs interact to affect performance (Step 1; see analysis under Performance), and that pro-diversity beliefs inspired greater elaboration in informationally diverse groups than pro-similarity beliefs (Step 2; see analysis under Information Elaboration). Next, we aimed to establish that the proposed mediator, information elaboration, predicted performance (Step 3). To do so, following Hull et al. (1992), we regressed performance on information elaboration (centered) as well as on informational diversity (dummy-coded) and the interaction between information elaboration and informational diversity. The statistics pertaining to this analysis are summarized in Table 2. This analysis revealed no main effects of information elaboration and informational diversity, but it did reveal a significant interaction. Simple slopes analysis showed that informationally diverse groups performed better when they elaborated more information, $§=$ $.47, t=2.60, p<.05$, whereas performance of informationally homogeneous groups was not affected by information elaboration, $ß=-.50, t=-1.82$, $n s$. This analysis thus confirms that more information elaboration may be associated with better performance, but that this is only 
the case in informationally diverse groups. These results point to the need to include the covariate interaction between information elaboration and informational diversity in the final step of the mediation analysis (Hull et al., 1992; Muller et al., 2005; Stevens, 1996; Yzerbyt et al., 2004).

For the final step of the mediation analysis, we regressed performance on diversity beliefs and informational diversity (both dummy-coded) and their interaction, as well as on information elaboration and on the interaction between information elaboration and informational diversity. This analysis yielded a significant Information Elaboration x Informational Diversity interaction, and the originally significant interaction between diversity beliefs and informational diversity was reduced to non-significance (see Table 2). In line with Hypothesis 3, this pattern of results indicates that the effect of diversity beliefs on performance in informationally diverse groups is mediated by information elaboration.

\section{Discussion}

Diverse information and perspectives in work groups can potentially boost group performance, but diverse groups are often unable to benefit from their diversity. Addressing this issue, we proposed that groups are more likely to effectively use their informational resources when group members believe in the value of diversity. We put this proposition to the test under conditions where groups were characterized by diversity faultlines (Lau \& Murnighan, 1998)--a situation widely assumed to stand in the way of groups' effective use of information (see van Knippenberg \& Schippers, in press). In support of our proposition, diversity beliefs moderated the relationship between informational diversity and performance, such that informationally diverse (but not informationally homogeneous) groups performed better when they held pro-diversity beliefs rather than pro-similarity beliefs.

While a number of scholars have argued that diversity beliefs and related constructs play an important role in teams (e.g., Ely \& Thomas, 2001; Kossek \& Zonia, 1993; van 
Knippenberg \& Haslam, 2003), a quantitative test of the moderating effect of diversity beliefs on the relation between diversity and group processes and performance was lacking. The present study thus provides an important next step in research on diversity beliefs, attitudes, perspectives, and climates. More generally, the present findings may be viewed as a contribution to attempts to identify the contingencies of the effects of work group diversity. Diversity research has not been overly successful in mapping the effects of work group diversity, and several authors have attributed this to the "main effects" approach that has characterized a lot of diversity research (Pelled et al., 1999; van Knippenberg, De Dreu et al., 2004; van Knippenberg \& Schippers, in press). The present focus on diversity beliefs as moderator of the effects of work group diversity may thus also be seen as testifying to the value of a focus on the contingencies of the effects of diversity.

We were also able to establish that the effect of diversity beliefs in informationally diverse groups was mediated by group elaboration of task-relevant information. Van Knippenberg, De Dreu et al. (2004) propose that information elaboration is the core process underlying the positive effects of diversity on group performance, and the present finding that informationally diverse groups were dependent on elaboration to perform well may thus be interpreted as important first evidence for their theoretical analysis. Moreover, the fact that pro-diversity beliefs engendered elaboration in informationally diverse groups corroborates our proposition that pro-diversity beliefs invite group members to actively capitalize on their groups' diversity.

Because faultlines were a constant in our study, we should be careful not to conclude that the present findings pertain to the effects of faultlines. Rather, our results concern group processes and performance under faultline conditions. Given what we know about the effects of faultlines (e.g., Lau \& Murnighan, 2005; Li \& Hambrick, 2005), the current focus on performance under faultline conditions provides a test of the effects of diversity beliefs in 
conditions under which diversity has often been found to disrupt group processes. If prodiversity beliefs can stimulate groups to use their informational diversity under faultline conditions, we might expect that pro-diversity beliefs are also able to boost diverse groups' performance under conditions that are less conducive to the disruptive effects of work group diversity.

In a related vein, the fact that diversity beliefs affected group performance under faultline conditions corroborates another point raised by van Knippenberg, De Dreu et al. (2004). They argue that salient subgroup categorizations in diverse groups as such are not problematic--the problem is intergroup bias that may, but need not, be engendered by subgroup categorization. Faultlines are generally assumed to render subgroup categorization salient, and the present findings might thus be interpreted as showing that salient subgroups need not be detrimental to group performance, and that diversity beliefs moderate the extent to which salient subgroups elicit detrimental group processes.

Although experiments are not conducted in a quest for external validity (Dipboye, 1990; Mook, 1983), reports of experimental research tend to elicit questions of external validity among their readership. Obviously, then, confidence in the conclusions advanced here could be bolstered when the current results were replicated in a study of teams in actual organizations, and this would indeed seem an important avenue for future research. In this respect, it is noteworthy that a previous study of work group diversity found similar effects of diversity beliefs on identification in both a lab experiment and a field study (van Knippenberg, Haslam et al., 2004). Likewise, Ely and Thomas' (2001) qualitative analysis of the role of diversity perspectives in organizations suggests that the effects of diversity beliefs observed in the present study also occur in the field. As always, however, the proof of the pudding is in the eating, and it would be valuable if future research would focus on the effects of diversity beliefs on team performance in the field. 
An interesting possibility in this respect is that the influence of diversity beliefs on diverse teams' performance might actually be greater in the field. In organizations, informationally diverse teams typically have a larger pool of information and perspectives than informationally homogeneous teams. Accordingly, when circumstances are conducive to the elaboration of task-relevant information, informationally diverse teams should be able to outperform informationally homogeneous teams (e.g., Jehn et al., 1999). This means that prodiversity beliefs might lead informationally diverse teams to outperform informationally homogeneous teams, because the former are likely to have more information at their disposal than the latter. This possibility could not be addressed in the present study, because providing informationally diverse groups with more information than informationally homogeneous groups would have confounded informational diversity with the amount of information available to the group. Although this confounding is likely to occur in organizations, it was undesirable for our purposes, because the aim of the present study was to show that diversity beliefs (and not the amount of information available) moderate the diversity-performance relationship. We expect that in organizations informationally diverse groups may outperform informationally homogeneous groups partly because they will often have more information, and we expect this to happen especially when they hold pro-diversity beliefs.

From an applied perspective, an important implication of the present findings is that the effective management of a diverse workforce should involve the management of diversity beliefs. For example, managers may foster pro-diversity beliefs by communicating their belief in the value of diversity and by explaining how task performance can benefit from diversity of information and perspectives. We should realize, however, that the present findings were obtained in ad hoc groups of students with presumably no strong beliefs about the implications of gender diversity for performance in decision-making tasks. Even though earlier studies on diversity beliefs and cultures in organizations suggest that diversity beliefs 
are malleable (Ely \& Thomas, 2001; van Knippenberg, Haslam et al., 2004), we should expect constraints with regard to the extent and the ease with which organizational members can be convinced of the value of particular dimensions of diversity. For instance, diversity is more valuable for more complex, knowledge-intensive tasks than for more simple, routine tasks (van Knippenberg \& Schippers, in press). Arguably, then, it should be more feasible for managers to explain the value of diversity in more complex tasks than in more routine tasks. Stereotypic beliefs may also stand in the way of pro-diversity beliefs (i.e., it might be hard to convince a person with racist beliefs of the value of ethnic diversity). Accordingly, while the present study suggests that fostering pro-diversity beliefs may be an important aspect of the successful management of diversity, more work clearly needs to be done to develop our understanding of the possibilities to foster pro-diversity beliefs in organizations.

In a related way, current results also have implications for diversity training programs. Diversity training could, in principle, exert an important influence on diversity beliefs. However, most diversity training programs seem to be limited to making people aware of their stereotypes about other groups and changing people's feelings and ideas about those groups (e.g., Karp \& Sammour, 2000; Kossek \& Lobel, 1996; Rynes \& Rosen, 1995). The current findings suggest that it is also important to manage people's feelings about diversity itself (rather than about different others) and to make them aware of the potential value of being a member of a diverse team. It would therefore seem worthwhile to extend diversity training programs beyond this focus on stereotypes to include a focus on beliefs about and attitudes toward diversity itself (cf. van Knippenberg, Haslam et al., 2004).

Given the potential benefits of a work force endorsing pro-diversity beliefs, an important direction for future research would seem to be to develop theory about the origins of diversity beliefs. At least three partly related antecedents of diversity beliefs are suggested by previous research. First, van Knippenberg, Haslam et al. (2004) identified task 
requirements as a source of diversity beliefs, showing that individuals working on a task that required diverse perspectives developed more positive attitudes toward diversity than did individuals who worked on a task that required homogeneous perspectives (cf. the notion that diversity is more beneficial on more knowledge-intensive tasks; e.g., van Knippenberg et al., 2004). Second, prior experience would seem to be a source of diversity beliefs. When people have positive experiences with working in a diverse group, it is likely that those experiences will shape their beliefs about diversity in the future. Finally, Flynn (2005) and Strauss et al. (2003) note that individual difference variables may affect beliefs about different ethnic groups and diversity in general. One variable that might be of interest in this context is openness to experience (e.g., Flynn, 2005). In sum, then, it would seem appropriate to explore individual differences as well as situational influences both internal and external to the work group as determinants of diversity beliefs. Considering these and other potential precursors of diversity beliefs may help to lay the foundations for successful diversity management in organizations. 


\section{References}

Argote, L., Gruenfeld, D., \& Naquin, C. (2000). Group learning in organizations. In M. E. Turner (Ed.), Groups at work: Theory and practice (pp. 369-211). Mahwah, NJ: Erlbaum.

Baron, R. M., \& Kenny, D. A. (1986). The moderator-mediator variable distinction in social psychological research: Conceptual, strategic, and statistical considerations. Journal of Personality and Social Psychology, 51, 1173-1182.

Bliese, P. D. (2000). Within-group agreement, non-independence, and reliability: Implications for data aggregation and analysis. In K. J. Klein \& S. W. J. Kozlowski (Eds.), Multilevel theory, research, and methods in organizations: Foundations, extensions, and new directions (pp. 349-381). San Francisco: Jossey-Bass.

Bowers, C. A., Pharmer, J. A., \& Salas, E. (2000). When member homogeneity is needed in work teams: A meta-analysis. Small Group Research, 31, 305-327.

Cicchetti, D. V., \& Sparrow, S. S. (1992). Developing criteria for establishing the interrater reliability of specific items in a given inventory: Applications to assessment of adaptive behavior. American Journal of Mental Deficiency, 86, 127-137.

Cox, T. H. (2003). Cultural diversity in organizations: Theory, research and practice. San Francisco, CA: Berrett-Koehler.

Dipboye, R. L. (1990). Laboratory vs. field research in industrial and organizational psychology. International Review of Industrial and Organizational Psychology, 5, 1-34.

Earley, P. C., \& Mosakowski, E. (2000). Creating hybrid team cultures: An empirical test of transnational team functioning. Academy of Management Journal, 43, 26-49.

Ely, R. J., \& Thomas, D. A. (2001). Cultural diversity at work: The effects of diversity perspectives on work group processes and outcomes. Administrative Science Quarterly, 46, 229-273. 
Flynn, F. J. (2005). Having an open mind: The impact of openness to experience on interracial attitudes and impression formation. Journal of Personality and Social Psychology, 88, 816-826.

Gaertner, S. L., Mann, J. A., Murrell, A. J., \& Dovidio, J. F. (1989). Reduction of intergroup bias: The benefits of recategorization. Journal of Personality and Social Psychology, 57, 239-249.

George, J. M. (1990). Personality, affect, and behavior in groups. Journal of Applied Psychology, 75, 107-116.

Glick, W. H. (1985). Conceptualizing and measuring organizational and psychological climate: Pitfalls in multilevel research. Academy of Management Journal, 10, 601-616.

Gruenfeld, D. H., Mannix, E. A., Williams, K. Y., \& Neale, M. A. (1996). Group composition and decision making: How member familiarity and information distribution affect process and performance. Organizational Behavior and Human Decision Processes, 67, 1-15.

Harrison, D. A., Price, K. H., \& Bell, M. P. (1998). Beyond relational demography: Time and the effects of surface- and deep-level diversity on work group cohesion. Academy of Management Journal, 41, 96-107.

Hinsz, V. B., Tindale, R. S., \& Vollrath, D. A. (1997). The emerging conceptualization of groups as information processors. Psychological Bulletin, 121, 43-64.

Homan, A. C., van Knippenberg, D., Van Kleef, G. A., \& De Dreu, C. K. W. (2006). Interacting dimensions of diversity: Cross-categorization as a strategy to enhance the functioning of diverse work groups. Manuscript submitted for publication, University of Amsterdam.

Hostager, T. J., \& De Meuse, K. P. (2002). Assessing the complexity of diversity perceptions: Breadth, depth, and balance. Journal of Business and Psychology, 17, 189-206. 
Hull, J. G., Tedlie, J. C., \& Lehn, D. A. (1992). Moderator variables in personality research: The problem of controlling for plausible alternatives. Personality and Social Psychology Bulletin, 18, 115-117.

Ilgen, D. R. (1999). Teams embedded in organizations: Some implications. American Psychologist, 54, 129-139.

Jackson, S. E., \& Associates (1992). Diversity in the workplace. New York, NY: Guilford Press. Jehn, K. A., Northcraft, G. B., \& Neale, M. A. (1999). Why differences make a difference: A field study of diversity, conflict, and performance in workgroups. Administrative Science Quarterly, 44, 741-763.

Johnson, D. W., \& Johnson, F. P. (1982). Joining together: Group theory and group skills (2nd ed.). Englewood Cliffs, NJ: Prentice-Hall.

Karp, H. B., \& Sammour, H. Y. (2000). Workforce diversity: Choices in training programs and dealing with resistance to diversity. College Student Journal, 34, 451-459.

Kashy, D. A., \& Kenny, D. A. (2000). The analysis of data from dyads and groups. In H. T. Reis \& C. M. Judd (Eds.), Handbook of research methods in social and personality psychology (pp. 451-477). Cambridge, UK: University Press.

Kossek, E. E., \& Lobel, S. A. (1996). Managing diversity: Human resource strategies for transforming the workplace. Oxford, UK: Blackwell.

Kossek, E. E., \& Zonia, S. C. (1993). Assessing diversity climate: A field study of reactions to employer efforts to promote diversity. Journal of Organizational Behavior, 14, 6181.

Lau, D., \& Murnighan, J. K. (1998). Demographic diversity and faultlines: The compositional dynamics of organizational groups. Academy of Management Review, 23, 325-340.

Lau, D., \& Murnighan, J. K. (2005). Interactions with groups and subgroups: The effects of 
demographic faultlines. Academy of Management Journal, 48, 645-659.

Li, J., \& Hambrick, D. C. (2005). Factional groups: A new vantage on demographic faultlines, conflict, and disintegration in work teams. Academy of Management Journal, 48, 794-813

Milliken, F. J., \& Martins, L. L. (1996). Searching for common threads: Understanding the multiple effects of diversity in organizational groups. Academy of Management Review, 21, 402-433.

Mook, D. G. (1983). In defense of external invalidity. American Psychologist, 5, 379-387.

Mor Barak, M. E., Cherin, D. A., \& Berkman, S. (1998). Organizational and personal dimensions of diversity climate: Ethnic and gender differences in employee perceptions. Journal of Applied Behavioral Sciences, 31, 82-104.

Muller, D., Judd, C. M., \& Yzerbyt, V. Y. (2005). When moderation is mediated and mediation is moderated. Journal of Personality and Social Psychology, 89, 852-863.

Pelled, L. H., Eisenhardt, K. M., \& Xin, K. R. (1999). Exploring the black box: An analysis of work group diversity, conflict and performance. Administrative Science Quarterly, 44, 1-28.

Phillips, K. W. (2003). The effects of categorically based expectations on minority influence: The importance of congruence. Personality and Social Psychology Bulletin, 29, 3-13. Phillips, K. W., Mannix, E. A., Neale, M. A., \& Gruenfeld, D. H. (2004). Diverse groups and information sharing: The effects of congruent ties. Journal of Experimental Social Psychology, 40, 497-510.

Rynes, S. L., \& Rosen, B. (1995). A field survey of factors affecting the adoption and perceived success of diversity training. Personnel Psychology, 48, 247-270.

Shrout, P. E., \& Fleiss, J. L. (1979). Intraclass correlations: Uses in assessing rater reliability. Psychological Bulletin, 86, 420-428. 
Stasser, G., \& Titus, W. (1985). Pooling of unshared information in group decision making: Biased information sampling during discussion. Journal of Personality and Social Psychology, 48, 1467-1478.

Strauss, J. P., Connerley, M. L., \& Ammermann, P. A. (2003). The "Threat Hypothesis", personality, and attitudes toward diversity. Journal of Applied Behavioral Science, 39, $32-52$.

Thatcher, S. M. B., Jehn, K. A., \& Zanutto, E. (2003). Cracks in diversity research: The effects of diversity faultlines on conflict and performance. Group Decision and Negotiation, 12, 217-241.

Turner, J. C., Hogg, M. A., Oakes, P. J., Reicher, S. D., \& Wetherell, M. S. (1987). Rediscovering the social group: A self-categorization theory. Oxford, UK: Blackwell. van Knippenberg, D., De Dreu, C. K. W., \& Homan, A. C. (2004). Work group diversity and group performance: An integrative model and research agenda. Journal of Applied Psychology, 89, 1008-1022.

van Knippenberg, D., \& Haslam, S. A. (2003). Realizing the diversity dividend: Exploring the subtle interplay between identity, ideology, and reality. In S. A. Haslam, D. van Knippenberg, M. Platow, \& N. Ellemers (Eds.), Social identity at work: Developing theory for organizational practice (pp. 61-77). New York and Hove: Psychology Press. van Knippenberg, D., Haslam, S. A., \& Platow, M. J. (2004, April). Unity through diversity: Value-in-diversity beliefs as moderator of the relationship between work group diversity and group identification. Paper presented at the Society for Industrial and Organizational Psychology 19th Annual Conference, Chicago.

van Knippenberg, D., \& Schippers, M. C. (in press). Work group diversity. Annual Review of Psychology.

Weingart, L. R. (1997). How did they do that? The ways and means of studying group 
processes. Research in Organizational Behavior, 19, 189-239.

Willemsen, T. M., \& Fischer, A. H. (1999). Assessing multiple facets of gender identity: The gender identity questionnaire. Psychological Reports, 84, 561-562.

Williams, K. Y., \& O'Reilly, C. A. (1998). Demography and diversity in organizations. Research in Organizational Behavior, 20, 77-140.

Yzerbyt, V. Y., Muller, D., \& Judd, C. M. (2004). Adjusting researchers approach to adjustment: On the use of covariates when testing interactions. Journal of Experimental Psychology, 40, 424-431. 


\section{Footnotes}

${ }^{1}$ A pretest with 23 students who did not participate in the main study showed that there was no difference between men and women on task performance, suggesting that the task is not gender-related, $F(1,22)=.29$, ns. Also, we assessed whether the participants themselves perceived performance on the task to be gender-related (i.e., more "male" or more "female"). A $t$ test showed that perceptions $(M=4.22, S D=0.90)$ did not differ from the midpoint of the scale $(t[22]=1.16, n s)$, indicating that participants did not perceive the task to be gender-related. Again, we found no difference in responses between men and women, $F(1,22)=.91, n s$.

${ }^{2}$ In a pretest $(N=22)$ we compared three different distributions of information (only information part A vs. only information part B vs. and information parts A and B) and found a significant effect on performance, $F(2,19)=6.73, p<.01, \eta^{2}=.42$ (lower scores reflect better performance). Post-hoc tests revealed that students who received all the information (i.e., parts A and B) did significantly better $(M=25.00, S D=6.68)$ than did those who read only information set A $(M=35.50, S D=8.60)$ or information set $\mathrm{B}(M=39.67, S D=8.24)$, with the latter two conditions not significantly differing from each other. These findings suggest that (1) information sets A and B are equally useful and informative when it comes to listing items needed for survival in the desert, and (2) people who are aware of the information in both sets perform better than do those who only know set A or set B.

${ }^{3}$ ANOVA revealed no effects of the experimental manipulations on the number of items generated, $F(1,42)=.41, n s$.

${ }^{4}$ ANOVA revealed no effects of the manipulation on the elaboration of shared information items, $F(1,41)=1.10$, ns. 
Table 1

Effects of Diversity Beliefs and Informational Diversity on Performance and Information Elaboration.

\begin{tabular}{|c|c|c|c|c|}
\hline \multirow[b]{2}{*}{ Measure } & \multicolumn{2}{|c|}{ Informationally Heterogeneous } & \multicolumn{2}{|c|}{ Informationally Homogeneous } \\
\hline & Pro-diversity & Pro-similarity & Pro-diversity & Pro-similarity \\
\hline & Belief & Belief & Belief & Belief \\
\hline Performance & $7.20(0.82)_{\mathrm{a}}$ & $6.04(0.74)_{b}$ & $6.70(1.07)_{\mathrm{ab}}$ & $6.64(0.94)_{a b}$ \\
\hline Information Elaboration & $31.55(5.82)_{\mathrm{a}}$ & $24.70(5.08)_{\mathrm{b}}$ & $23.64(3.56)_{b}$ & $24.54(4.29)_{b}$ \\
\hline
\end{tabular}

Note. Means within a row with a different subscript differ at $p<.05$. Performance ranges from 0 (poor) to 12 (excellent). Information Elaboration ranges from 0 (no elaboration) to 40 (high elaboration). Performance represents the mean number of points obtained per item. 
Table 2

Summary of Hierarchical Regression Results of Mediational Analysis

Predictors Performance Step 3

\begin{tabular}{llll}
$\mathrm{B}(S E)$ & $\beta$ & $t$ & $R^{2}$ \\
\hline & & $.20^{*}$
\end{tabular}

Informational Diversity

$\begin{array}{rrr}-.06(0.29) & -.30 & -0.19 \\ -.09(0.05) & -.50 & -1.82 \\ .17(0.06) & .77 & 2.93^{*}\end{array}$

Predictors Performance Step 4

$.27 *$

Diversity Beliefs

Informational Diversity

Diversity Beliefs x Informational Diversity

$\begin{array}{rrr}-.46(0.39) & -.24 & -1.18 \\ -.02(0.37) & -.01 & -0.05 \\ .91(0.65) & .39 & 1.40 \\ -.09(0.05) & -.49 & -1.83 \\ .13(0.07) & .58 & 2.02 *\end{array}$

$* p<.05$ 


\section{Figure Captions}

Figure 1. Group performance as a function of informational diversity and diversity beliefs.

Figure 2. Information elaboration as a function of informational diversity and diversity beliefs. 
Diversity Beliefs and Performance 35

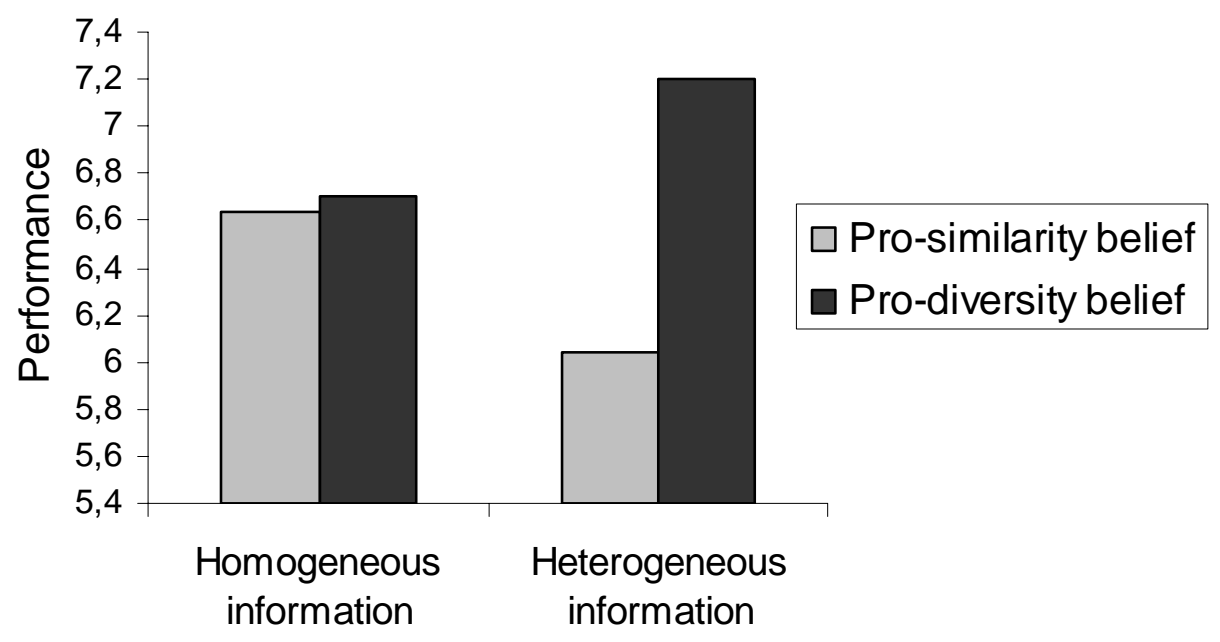




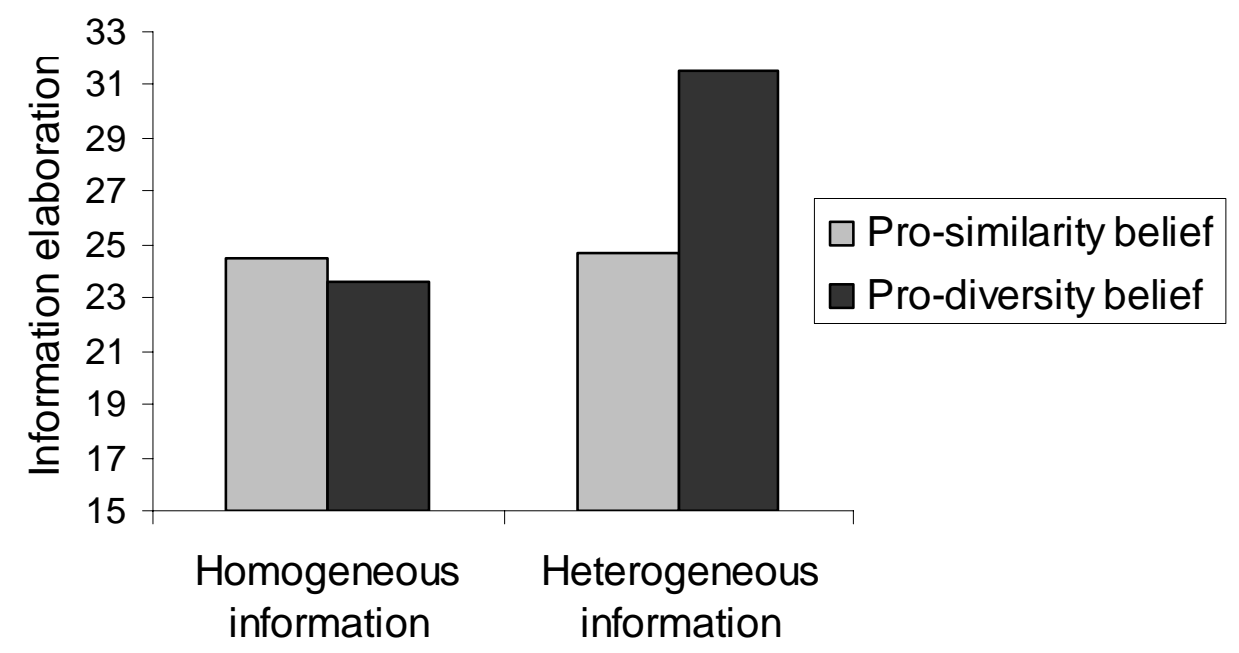




\section{Publications in the ERIM Report Series Research* in Management}

\section{ERIM Research Program: "Organizing for Performance"}

\section{6}

IPRs, Technological Development, and Economic Development

Wilfred Dolfsma

ERS-2006-004-ORG

http://hdl.handle.net/1765/7301

Institution Building and Change in China

Barbara Krug and Hans Hendrischke

ERS-2006-008-ORG

http://hdl.handle.net/1765/7331

Rational Entrepreneurship in Local China: Exit Plus Voice for Preferential Tax Treatments

Ze Zhu, George W.J. Hendrikse and Barbara Krug

ERS-2006-010-ORG

http://hdl.handle.net/1765/7577

A Process Model of Locational Change in Entrepreneurial Firms: An Evolutionary Perspective Erik Stam

ERS-2006-014-ORG

http://hdl.handle.net/1765/7633

Starting Anew: Entrepreneurial Intentions and Realizations Subsequent to Business Closure Veronique Schutjens and Erik Stam

ERS-2006-015-ORG

$\underline{\text { http://hdl.handle.net/1765/7638 }}$

Agglomeration Economies and Entrepreneurship in the ICT Industry

Frank G. van Oort and Erik Stam

ERS-2006-016-ORG

http://hdl.handle.net/1765/7639

Renascent Entrepreneurship

Erik Stam, David Audretsch and Joris Meijaard

ERS-2006-017-ORG

http://hdl.handle.net/1765/7640

Social Life of Values

Slawomir Magala

ERS-2006-019-ORG

http://hdl.handle.net/1765/7645

Enterprise Ground Zero in China

ERS-2006-024-ORG

Barbara Krug

$\underline{\text { http://hdl.handle.net/1765/7853 }}$

Framing China: Transformation and Institutional Change

ERS-2006-025-ORG

Barbara Krug and Hans Hendrischke

http://hdl.handle.net/1765/7854 
Currents and Sub-currents in the River of Innovations - Explaining Innovativeness using New-Product Announcements Wilfred Dolfsma and Gerben van der Panne

ERS-2006-036-ORG

http://hdl.handle.net/1765/7943

Much Ado About Nothing: A conceptual critique of CSR

J. (Hans) van Oosterhout and Pursey P. M. A. R. Heugens

ERS-2006-040-ORG

http://hdl.handle.net/1765/7894

The Effect of Business Regulations on Nascent and Young Business Entrepreneurship

André van Stel, David J. Storey and A. Roy Thurik

ERS-2006-052-ORG

http://hdl.handle.net/1765/7996

Postmaterialism Influencing Total Entrepreneurial Activity across Nations

Lorraine Uhlaner and A. Roy Thurik

ERS-2006-062-ORG

http://hdl.handle.net/1765/8128

The Lag Structure of the Impact of Business Ownership on Economic Performance in OECD Countries

Martin Carree and A. Roy Thurik

ERS-2006-064-ORG

http://hdl.handle.net/1765/8126

Uncertainty Avoidance and the Rate of Business Ownership Across 21 OECD Countries, 1976-2004

Sander Wennekers, A. Roy Thurik, André van Stel and Niels Noorderhaven

ERS-2006-065-ORG

http://hdl.handle.net/1765/8125

Interacting Dimensions of Diversity: Cross-Categorization and the Functioning of Diverse Work Groups Astrid C. Homan, Daan van Knippenberg, Gerben A. Van Kleef and Carsten K. W. De Dreu ERS-2006-069-ORG

http://hdl.handle.net/1765/8500

Group Member Prototypicality and Intergroup Negotiation: How One's Standing in the Group Affects Negotiation Behaviour Gerben A. Van Kleef, Wolfgang Steinel, Daan van Knippenberg, Michael A. Hogg and Alicia Svensson

ERS-2006-070-ORG

http://hdl.handle.net/1765/8502

Bridging Faultlines by Valuing Diversity: Diversity Beliefs, Information Elaboration, and Performance in Diverse Work Groups Astrid C. Homan, Daan van Knippenberg, Gerben A. Van Kleef and Carsten K. W. De Dreu ERS-2006-071-ORG

http://hdl.handle.net/1765/8496

Affective Match: Leader Emotional Displays, Follower Positive Affect, and Follower Performance

Frederic Damen, Barbara van Knippenberg and Daan van Knippenberg

ERS-2006-072-ORG

http://hdl.handle.net/1765/8499

Leadership and Fairness: The State of the Art

Daan van Knippenberg, David De Cremer and Barbara van Knippenberg

ERS-2006-073-ORG

http://hdl.handle.net/1765/8501 
* A complete overview of the ERIM Report Series Research in Management: https://ep.eur.n//handle/1765/1

ERIM Research Programs:

LIS Business Processes, Logistics and Information Systems

ORG Organizing for Performance

MKT Marketing

F\&A Finance and Accounting

STR Strategy and Entrepreneurship 